Volume 2

Number 1 Secrecy and Intelligence

Article 3

September 2018

\title{
Troping the Enemy: Metaphor, Culture, and the Big Data Black Boxes of National Security
}

Robert Albro

American University, robert.d.albro@gmail.com

Follow this and additional works at: https://scholarworks.sjsu.edu/secrecyandsociety

Part of the Anthropological Linguistics and Sociolinguistics Commons, Digital Humanities Commons, Language Interpretation and Translation Commons, Linguistic Anthropology Commons, Modern Languages Commons, Other Languages, Societies, and Cultures Commons, Science and Technology Studies Commons, and the Social and Cultural Anthropology Commons

\section{Recommended Citation}

Albro, Robert. 2018. "Troping the Enemy: Metaphor, Culture, and the Big Data Black Boxes of National Security." Secrecy and Society 2(1). https://doi.org/10.31979/

2377-6188.2018.020103 https://scholarworks.sjsu.edu/secrecyandsociety/vol2/iss1/3

This Special Issue Article is brought to you for free and open access by the School of Information at SJSU ScholarWorks. It has been accepted for inclusion in Secrecy and Society by an authorized administrator of SJSU ScholarWorks. For more information, please contact scholarworks@sjsu.edu. 


\title{
Troping the Enemy: Metaphor, Culture, and the Big Data Black Boxes of National Security
}

\author{
Abstract \\ This article considers how cultural understanding is being brought into the work of the \\ Intelligence Advanced Research Projects Activity (IARPA), through an analysis of its \\ Metaphor program. It examines the type of social science underwriting this program, \\ unpacks implications of the agency's conception of metaphor for understanding so-called \\ cultures of interest, and compares IARPA's to competing accounts of how metaphor works \\ to create cultural meaning. The article highlights some risks posed by key deficits in the \\ Intelligence Community's (IC) approach to culture, which relies on the cognitive linguistic \\ theories of George Lakoff and colleagues. It also explores the problem of the opacity of \\ these risks for analysts, even as such predictive cultural analytics are becoming a part of \\ intelligence forecasting. This article examines the problem of information secrecy in two \\ ways, by unpacking the opacity of "black box," algorithm-based social science of culture for \\ end users with little appreciation of their potential biases, and by evaluating the IC's \\ nontransparent approach to foreign cultures, as it underwrites national security \\ assessments.
}

\section{Keywords}

culture, forecasting, IARPA, Intelligence Advanced Research Projects Activity, intelligence analysis, Intelligence Community, metaphor, national security 


\title{
Troping the Enemy: Metaphor, Culture, and the Big Data Black Boxes of National Security
}

Robert Albro

\begin{abstract}
This article considers how cultural understanding is being brought into the work of the Intelligence Advanced Research Projects Activity (IARPA), through an analysis of its Metaphor program. It examines the type of social science underwriting this program, unpacks implications of the agency's conception of metaphor for understanding so-called cultures of interest, and compares IARPA's to competing accounts of how metaphor works to create cultural meaning. The article highlights some risks posed by key deficits in the Intelligence Community's (IC) approach to culture, which relies on the cognitive linguistic theories of George Lakoff and colleagues. It also explores the problem of the opacity of these risks for analysts, even as such predictive cultural analytics are becoming a part of intelligence forecasting. This article examines the problem of information secrecy in two ways, by unpacking the opacity of "black box," algorithm-based social science of culture for end users with little appreciation of their potential biases, and by evaluating the IC's nontransparent approach to foreign cultures, as it underwrites national security assessments.
\end{abstract}

\section{Keywords}

culture, forecasting, IARPA, Intelligence Advanced Research Projects Activity, intelligence analysis, Intelligence Community, metaphor, national security

Social and behavioral scientists engaged with cultural topics would do well to pay more attention to the research portfolio of the little-known Intelligence Advanced Research Projects Activity (IARPA), ${ }^{1}$ established in

\footnotetext{
${ }^{1}$ To date there has been very little, if any, research focused on IARPA itself, though at this
} point the agency's long tail of publications based on programs it has funded continues to 
Secrecy and Society, Vol. 2, No. 1 [2018], Art. 3

2006 in the spirit of the Pentagon's much better known and high-tech

DARPA, to sponsor high-risk, high-payoff research leading to groundbreaking technologies to support an "overwhelming intelligence advantage over future adversaries" (IARPA n.d.a). Operating under the Office of the Director of National Intelligence as the intelligence community's research wing, IARPA has been funding research and applications for use by the U.S.'s sixteen spy agencies to address social scientific problems. These include the development of a suite of programs and tools that combine current approaches in neuroscience, big-data text mining, natural language processing, and machine learning to generate analyses of "cultures," and to dramatically improve intelligence forecasting.

As the agency's first acting director, Steve Nixon, explained in 2007, IARPA's portfolio includes funding work "to help analysts measure cultural habits of another society" (cited in Shrader 2007). Relevant projects include the current "Cyber-Attack Automated Unconventional Sensor Environment" (CAUSE), which aims to forecast and detect cyber-attacks sooner than is currently possible, in part by accounting for "cyber-actor behavior and cultural understanding" (IARPA n.d.b). A 2012 project, "Knowledge Representation in Neural Systems" (KRNS), was dedicated to improving the training and performance of intelligence analysts through a better understanding of "how the human brain represents conceptual knowledge"

grow. Investigative journalists covering U.S. national security institutions have, on occasion, taken note of IARPA's work (Weinberger 2011). 
(IARPA n.d.c), or semantic knowledge, by using neural imaging to improve analysts' interpretations of mental representation schemes across diverse semantic contexts, or cultures. The 2009 "Reynard" program aspired to produce "virtual world" behavioral indicators that identify "real world" (IARPA n.d.d) characteristics of individuals and groups, including cultural attributes. Yet another 2009 program, "Socio-Cultural Content in Language" (SCIL), sought to better correlate social goals with both language forms and content, including the ways that "language use reflects social and cultural norms" (IARPA n.d.e). Building on that program, the agency's 2011 "Metaphor" Project sought to automate the collection of large corpora of select native-language texts in order to compile repositories of metaphors to "better understand the shared concepts and worldviews of members of other cultures of interest" (IARPA n.d.f). ${ }^{2}$ These, and other agency programs, add up to a concerted years-long effort by IARPA to improve the cultural understanding of intelligence analysts.

This program was initiated with a Proposer's Day Briefing in April, 2011, featuring a presentation by IARPA staff as well as at least 11 government and non-governmental research laboratories or centers familiar with the needs of the intelligence community, and specializing primarily in computational and information sciences, including natural language processing and technologically enhanced approaches to risk assessment. A Broad Agency Announcement followed in May 2011, and grants were awarded to at least five teams from Carnegie Mellon, the Illinois Institute of Technology, Raytheon BBN Technologies, the State University of New York's Research Foundation, and the University of California-Berkeley. To date, this has resulted in approximately 50 publicly available peer reviewed publications, the vast majority of which describe efforts to build and to test data collection algorithms to automate the construction of metaphor repositories for different cultures. 
To echo the anthropologist Hugh Gusterson's (2010, 279) assessment of the broader cultural turn by U.S. security agencies in the global war on terror, IARPA's ambition to measure cultural habits on a large scale seeks "algorithmic solutions to hermeneutical problems," which, at the very least, take for granted a starkly different conception of culture as a source of insight than is found in contemporary anthropology. These differences are not trivial. "Culture" is a concept from which U.S. academic anthropology notably retreated in the 1990 s and which, while not dropping it altogether, the discipline has continued to qualify in multiple ways. Meanwhile, a focus upon "sociocultural factors" - often as "cultural intelligence" and as enlisted in diverse exercises of prediction - has become a priority in different corners of the military, security, and intelligence communities since at least the mid2000s (e.g., Albro and Ivey 2014; Albro 2011). Understanding why the Intelligence Community (IC) appears to be embracing the culture concept just as academic anthropology increasingly holds it at arm's length helps to illuminate important differences between the worlds of academe and the intelligence community regarding the significance of the culture concept itself, including perceived possibilities and limits to the type and extent of interpretation of cultures for the U.S. national security state.

Here I consider IARPA's Metaphor Program in greater depth because it is a particularly revealing example of critical analytic challenges posed by the recent technologically enhanced version of the cultural turn by the U.S. 
intelligence community. Most simply, a metaphor is a way to understand one thing in terms of another, as a linguistic relationship of similarity, where one experiential domain (the target) is understood by way of reference to another (the source). Nietzsche's $(1999,146)$ description of truth as a "mobile army of metaphors" is itself a metaphor, with truth now subject to the tactics of the rhetorical battlefield. Plentiful examples range from Homer's "wine-dark sea" to reference a sunset over water to astronomer Fred Hoyle coining the term "big bang" to refer to an influential theory for the universe's origin; computer programmers borrowing the notion of "Maxwell's demon" to describe software that runs in the background; understanding the relation of the state to its citizens in terms of a "strict father" or "nurturant parent" (see Lakoff 2002, 65); or, in Tagalog, "to have a soft nose" as a reference to especially gullible people.

IARPA's goal of automating "the analysis of metaphorical language" (McCallum-Bayliss 2011) for use in intelligence forecasts raises pertinent questions about the meaning of metaphor and art of the possible in predictive cultural analytics, given competing scholarly approaches to metaphor theory. As I go on to unpack this, at issue are contending views of metaphor ${ }^{3}$ : On the one hand are cognitive linguists, often inspired by the

This article seeks to unpack the implications of IARPA's account of metaphor for cultural analysis by agencies of the U.S. national security state. In so doing, it contrasts two broad bodies of academic research on metaphor (and to some extent, analogic reasoning), characteristic of cognitive linguistics, on the one hand, and philosophers of literature or language (and to some extent, interpretive anthropology), on the other. These contrastive approaches represent two major accounts of how metaphors work and are meaningful, and 
work of George Lakoff and colleagues, addressing semantic problems of meaning in sentences and focused on the work of conceptual metaphors, assumed to be conventional, pervasive, and iterative; on the other are pragmatic theories of metaphor concerned with meaning in utterances and associated with such philosophers of language as Richard Rorty, Max Black, or Donald Davidson, and anthropologists such as James Fernandez, which, in Paul Ricoeur's $(1976,52)$ words, treat metaphor not as conventional but as an "instantaneous creation" and "impertinent predication" with no status in "already established language." As will become clear, it is no coincidence that IARPA's program builds on Lakoff's work but appears uninterested in or unaware of questions raised by debates around his work, or of the larger field of metaphor studies.

\section{Secrecy, Semiotics, and Silos}

IARPA's Metaphor program, and comparable agency initiatives, help us to appreciate notable changes in the production of secret information among U.S. national security agencies, or as Birchall $(2016,3)$ has phrased it, the evolving and historically contingent social relations of "concealment and revelation" informing and shaping the national security state. Today, these relations include such interacting priorities as the broad shift from Cold War

\footnotetext{
have influenced most, if not all, of the many schools of thought about metaphor. The article, therefore, addresses a crucially central question about the kind of cultural work performed by metaphors. A review of the bodies of work in international relations and elsewhere that touch on metaphor or analogy, however, is beyond the scope of this discussion.
} 
to counterterrorist operations, and an ongoing emphasis on technological or engineered problem-solving and big data collection, which has extended to a new focus on cultural analysis in response to perceived hard-to-identify threats among culturally distinct foreign groups - all of which impact wellestablished analytic approaches to intelligence forecasting.

"Technological fetishism" is of course not a new feature of the U.S. approach to national security (see Comor 2017). But Fosher (2014) and others have noted the growing entrenchment of "science and technology"based solutions in efforts to meet the challenges of cultural analysis in the security context, in which cultural information is often treated as available and classifiable raw data to be vacuumed up, typically from the Internet, by way of new, automated, big-data, computational collection tools. As I explore here, the advancing role played by technology in generating secret information itself adds new dimensions to the challenges posed by secrecy, through the opaque transformation of categories of analysis - such as culture - as these are tailored to the needs of the computational process itself.

Rapidly emerging computational tools are increasingly responsible for the generation of huge troves of secret information informing intelligence analysis and forecasting. These tools are creating new dilemmas for the relationship between transparency, secrecy, and security, beyond the nowfamiliar debates about privacy and data mining of personal information by 
U.S. national security agencies (see Plemmons and Albro 2012). Too often, these algorithmic tools function as "technological black boxes" (National Research Council 2011, 76), assumed to generate relevant data, but through poorly understood and highly technical computational processes, which are too often obscure to the analysts interpreting such data. ${ }^{4}$ The pervasiveness of such technological problem-solving for information collection and national security analysis is changing the relationship between intelligence analysts and their primary sources of data by partially concealing the collection process from analysts' ability to responsibly assess its integrity and thus value.

By "black box," I mean the technical attributes and performance parameters of the coding that informs big data tools, which invisibly enable some analytic pathways and not others, and which are, to a large extent, not transparent to typical end users. This is what Genevieve Bell $(2015,7)$ refers to in part when discussing the "secret life of data" in the emerging big-data context. This is not a problem, in Maret's $(2016,1)$ terms, of the "intentional or unintentional concealment of information," as it is of the technologically enhanced opacity of the backstage, for how secret

\footnotetext{
${ }^{4}$ An important source of this opacity is the fact that these algorithmic black boxes consist of computer code. In the design of big-data tools intended to identify and classify specific kinds of data-such as cultural information - expertise in constructing such computational tools, therefore, is often prioritized over that of subject matter experts, for example, in social scientific fields concerned with culture. In turn, such computationally generated cultural data are then provided for use by analysts with professional backgrounds in international relations, political science, or other subject area backgrounds typical for careers in international affairs, but who are not necessarily proficient computer programmers.
} 
information is generated for use by analysts. This opacity increases the risk of analysts fundamentally misrepresenting the behavior of cultural groups (see National Research Council 2011; Simonite 2017), which in turn increases the likelihood of poor national security decision-making with respect to so-called "cultures of interest."

These increasingly technological regimes of secrecy affect the very hermeneutics of intelligence analysis and its characteristic processing of information, from collection to description, reporting, and the generation of estimates through the so-called "intelligence cycle" (see Johnston 2005, 45). The idea that analysts ever inherited something like "raw data" (Johnston $2005,35)$ from collectors has served to obscure greater attention to the vagaries of so-called "sources and methods" in the field, which now include the intervention of big-data tools. Any claim that - for the case of culture "raw, objective, and unstructured" (National Research Council 2011, 78) data are what such tools identify and process is highly misleading. We are far from the transparency of a message "without distortion or modification" (Black 1988, 134). To bring the contingencies of big data generation into better view we should, as Gitelman and Jackson $(2013,4)$ suggest, look "under data to consider their root assumptions," in this case, prising open the algorithmic black boxes of computational cultural initiatives in the IC.

IARPA's Metaphor Program illustrates the familiar analogy between the organization of the national security state and so-called "secret societies" 
Secrecy and Society, Vol. 2, No. 1 [2018], Art. 3

(see Masco 2010), in which social relations and information are controlled, compartmentalized, and circulated - in Birchall's (2016, 2) words, in "highly ritualized" ways. The choice of metaphor as a recognized formulaic, ritual, or poetic form of speech, in contrast to ordinary speech, is itself an interpretive debate informing the program. The priority given to "mapping" metaphors which I explore in more depth below - combines metaphors, as particularly formulaic speech, with maps, as highly structured visualization tools and analogues of cultures, and helps to establish the material and meaningful "limits of revelation" (Birchall 2016, 9) of the collection and interpretation of big data-type cultural information, for use in the national security context. As the program's designers point out, efforts to recognize cultural norms are particularly challenging "because they tend to be hidden" (IARPA n.d.f). And the program draws attention to the changing frontier of what Masco $(2010,433)$ refers to as the "public/secret divide" in semiotic terms, that is, at the level of how cultural information is identified, and how analytic meanings are generated and circulated in the IC. But the semiotics of secrecy have taken on particular characteristics, reproduced in the assumptions of large-scale computational cultural analysis, and which reflect pervasive expectations in the era of counterterrorism.

One of these is the "needle in a haystack" problem, in which timesensitive, critical information is understood to be at once in plain sight but invisible to intelligence collecting efforts, because it is not found in rival 
national security states or militaries, but dispersed in or circulating through publics, societies, communities, religions, ethnic groups, or global networks. This has prompted technological efforts to collect better information about "the whole haystack" to uncover previously unperceived or unknown "hidden patterns" (Ophir 2016) - for example, about cultures of interest - by building archives of their metaphoric expression. Whether haystacks, as updated and particularly porous versions of the well-known container metaphor, in fact help to describe the challenges of analysis and interpretation in the IC today (see Logan 2017), they do help us to appreciate the IC's understanding of the generation of cultural meaning as a new kind of secret information.

\section{Lakoff's Tristes Tropes}

Lakoff's influence upon IARPA's program was pervasive from its inception. While he is not mentioned in the Broad Agency Announcement for the grant competition - no one is - his approach to metaphor, most obviously the distinction between "linguistic" and "conceptual" metaphors (which I will discuss in more detail), is introduced into the definitional framework for the announcement and as part of the 2011 Proposer's Day Briefing to research teams hoping to apply. His work is cited as a theoretical starting point by over half of the more than fifty peer-reviewed articles IARPA lists as results for this funded research program. And Lakoff himself served as a core team member for one such IARPA-funded project, a 
metaphor repository called MetaNet, which was in turn used by other computational researchers to provide metaphors as source data. First, therefore, we need to understand a few things about the Lakovian approach to metaphor and its relationship to IARPA's program, as there are other contenders in the scholarly field of trope theory.

Lakoff's signature theory of metaphor was first elaborated in his influential Metaphors We Live By, co-authored with Mark Johnson in 1980, in which he rejected a view of metaphor as a merely ornamental turn of phrase in the spirit of Cleanth Brook's "well-wrought urn" - the domain of poets and novelists - instead influentially demonstrating that "metaphor is pervasive in everyday life" (Lakoff and Johnson 1980, 3). Throughout Lakoff's body of work, conceptual metaphors are typically understood to solve routine problems of inference and reference by treating a more abstract topic (e.g., politics) as a target for a more concrete concept (e.g., family), which serves to frame our understanding of the target (see Lakoff 1993). This is a deceptively simple relation. Metaphor, in Lakoff's view, is not just a case of understanding one thing in terms of another. It is, rather, a way of inferring meaning about what is otherwise insubstantial, poorly understood, or little known - what literary critic Kenneth Burke (1989, 250), referring to metaphor, called "the realm of the incorporeal, invisible, intangible" - by way of a detour through familiar domains of concrete experience, or everyday 
sensible experience of the physical world, often of the body itself (Lakoff and Johnson 1980,56$)$.

The anthropologist James Fernandez $(1986,62)$ has, in similar fashion, explained metaphor as a way of engaging with and attributing meaning to otherwise "inchoate pronouns." Although Lakoff and Fernandez sharply disagree over how metaphorical processes work and what metaphors signify (a disagreement to which I will return), Fernandez's definition usefully clarifies because it highlights why attention to metaphor - formerly a woolly concept from the humanities and source of arguments among literary critics - might be of interest to IARPA and relevant in the national security context: Metaphorical relations are a device of self-definition of otherwise hard-to-classify social subjects. If, as Lakoff and IARPA take for granted, metaphoric predication is systematic, it is also predictable, and thus a promising avenue for gaining a better predictive handle on the culturally informed reasoning of little-understood groups.

Importantly, in Lakoff's account, conceptual metaphors also underpin families of related metaphorical expressions that appear more directly on the surface of our language use, which Lakoff calls linguistic metaphors. When we deploy metaphoric language in discourse, for Lakoff $(1993,244)$ these are mere "surface manifestations" of more fundamental cognitive habits. Throughout a long and productive career, his cognitive approach to metaphor has been further elaborated in a series of widely referenced 
Secrecy and Society, Vol. 2, No. 1 [2018], Art. 3

academic works that have explored how metaphors (and thus language) systematically connect to concepts (and thus thought). As Lakoff has characteristically noted, "Metaphor is not just a matter of language but of thought and reason" (Lakoff 1993, 208). The strong link that Lakoff draws between linguistic expressions and patterns of thought is significant for our purposes, because a major source for the appeal of Lakoff's approach in the IARPA context is the claim that attention to the metaphors used by a particular group of people is a promising doorway for understanding how these people - the IARPA program identifies a particular interest in speakers of English, Mexican Spanish, Russian, and Farsi - think about the world and are likely to make sense of future events.

Indeed, as the project's program manager, herself a linguist, put it in her Proposer's Day presentation to potential applicants, the program seeks to better understand "the use of metaphorical language to gain insights into understanding culture" (McCallum-Bayliss 2011). What this means for IARPA is that the agency seeks to stockpile and analyze metaphors that "expose insight into the views and goals" of protagonists in scenarios of concern to the intelligence community. Or, as a presentation by CENTRA Technology, Inc. (a risk assessment firm that works with the U.S. intelligence community) more bluntly put the matter, the large-scale machine language collection of metaphors promises to offer predictive insights into "the decision-making and perception of foreign actors as they affect security 
issues of interest to the United States" (CENTRA Technology, Inc., n.d.). Building directly on Lakoff's approach, IARPA understands the perceived systematic predictability of metaphorical relationships as a way to better understand and anticipate the behavior of relevant members of other cultures of interest to the national security state.

One of Lakoff's best known examples of metaphor, which he and colleagues develop in several places (Lakoff and Johnson 1980, 29-32; Lakoff 1987, 271-73; Lakoff 1993, 209), is the ubiquitous container, or conduit, metaphor. Lakoff explains that English speakers in the United States, for example, tend to describe the content of an argument metaphorically by referring to the language of containers. This is the case for such colloquial expressions as "That argument has holes in it" and "Your argument won't hold water" (Lakoff and Johnson 1980, 92). Thus, containers are used frequently as metaphors for anything with an inside and outside, or capable of holding something else, and when describing content in terms of "amount, density, centrality, and boundaries" (Lakoff and Johnson 1980, 95). The extension of such container logic or conduit thinking is built into Lakoff's understanding of metaphoric coherence, as a means of imagining iterative schemes of extension and inclusion of boxes within boxes, or vehicles of connection.

This is another appealing dimension of Lakoff's approach, as it is one way in which multiple metaphoric relationships help to form coherent 
conceptual structures, or patterns, with respect to how people think. As he has often stressed, Lakoff is not just interested in metaphors per se, but in identifying "a coherent system of metaphoric concepts" (Lakoff and Johnson $1980,9)$. Such coherence is assured, in Lakoff and Johnson's account, by the metaphoric generation of cultural meanings, which are understood to be shared in the same ways across the members of a population, functioning as what IARPA calls the previously hidden or unknown "tacit backdrop" of "underlying beliefs and worldviews" (IARPA 2011,4) of different linguistic and cultural groups.

\section{Machines Learning Metaphors and Déjà Vu}

IARPA would like to be able to data mine online texts on a large scale, as a "rich source for identifying cultural beliefs" (McCallum-Bayliss 2011) about key societies of interest, and to develop new automated techniques to identify, map, and then analyze the metaphorical language of mined online native-language text. Metaphors are the program's choice, because IARPA assumes (with Lakoff and company) that they are both "pervasive in everyday language" and "shape how people think about complex topics" (IARPA n.d.f). IARPA understands metaphors as a way to "reduce the complexity of meaning" precisely because their usage is systematic and patterned. At the Proposer's Day brief, linguistic metaphors were defined as the expressive "realizations of the underlying pattern or systematic 
association of abstract concepts" that in turn form a set of relationships "defined by mapping principles" (McCallum-Bayliss 2011). IARPA sees potential in such a mapping exercise because accurate maps promise predictability. Notably, mappability - the potential to transform cultural information into a cartographic asset and easily consultable visualization tool- has in recent years become a recurrent goal of national security actors (see Albro 2010, 1090; Holmes-Eber 2014).

Indeed, Lakoff's (1993) cognitive approach emphasizes how metaphor systematically connects language to thought through a set of mappable correspondences. Mapping in the Lakovian mode refers to the patterned set of correspondences governing relations of source and target domains. As Lakoff $(1993,207)$ has observed, metaphors illustrate a "systematic" and "tightly structured" mapping between source and target domains, and across conceptual domains. As mappings and sets of conceptual correspondences, Lakoff understands groups or families of metaphors in a given language to consistently express the same kinds of fundamental conceptual relationships (e.g., the logic of containers or conduits). These include predictable "crossdomain pairings of words and of inference patterns" (Lakoff 1993, 210). Importantly, Lakoff and Johnson describe these mapped sets of correspondences as highly stable "fixed-form expressions," which are "fixed by convention" (Lakoff and Johnson 1980, 52-54). For a given speech community, in other words, these "cross-domain mappings" follow 
Secrecy and Society, Vol. 2, No. 1 [2018], Art. 3

conventional rules of association and are built up into a semantic system, patterned and coherent but static, which we might otherwise label a "culture."

To better appreciate some of the difficulties of this approach for understanding culture, we need to detour briefly into the methodological weeds to touch ground with some of the ways the Lakoff-IARPA vision of metaphor has been put into practice. The basic task for research teams was to design, build, and maintain a "metaphor repository" for a given language, against which analysts would eventually and ideally be able to compare "real-life statements" (International Computer Science Institute n.d.) to predict intentions of people who may represent a threat to the United States. Perhaps the best-known of these is MetaNet (see Narayanan 2012), an IARPA-funded archive of searchable and interrelated metaphors hosted by the Berkeley-affiliated International Computing Science Institute. Lakoff was himself the linguistic analysis lead for the MetaNet development team, and the tool has attempted to operationalize his approach to metaphor. MetaNet has also been used by multiple other research teams engaged in similar work as a source archive of metaphors. As the team itself explains, MetaNet is intended to detect, categorize, analyze, and draw inferences, with the eventual goal of making "detailed predictions on the manner, content, and timing of metaphoric inference" (International Computer Science Institute n.d.) across languages and cultures. 
Significantly, an initial phase in the development of such metaphor repositories is to "bootstrap" or "seed" them, for the case of MetaNet, with representative metaphors from English, Farsi, Russian, and Spanish. This is a crucial step for understanding the interpretive parameters and possibilities for MetaNet-like projects. As computational linguist and team member Ekaterina Shutova (2010) clarifies, the archive is intended as a resource to identify, with minimal supervision, metaphoric expressions at the lexical level in clusters of co-occurring words, primarily nouns and verbs. It must rely on "seed metaphoric expressions" (Narayanan 2012), and its functionality and effectiveness are directly "dependent on its seed metaphors." As another IARPA-funded researcher notes, "Corpus linguists need some kind of given entity, a word, phrase, or pattern, to start out from" (Wikberg 2008, 34), which is why consideration of explicitly "innovative metaphors" is often excluded from such studies in favor of "predefined semantic and domain knowledge" (Gandy et al. 2013, 329).

"Seeding" a repository is itself a fascinating example of the container or conduit metaphor made famous in cognitive linguistic circles by Lakoff. The linguist William Foley $(1997,184-85)$ describes how container metaphors like seeds, with their "interior, boundary, and exterior," are often used in semiotics and linguistics to frame "the relationship between a word and its meaning," as "like a container and its contents." Foley $(1997,187)$ treats these theories of meaning as themselves expressions of an influential 
Secrecy and Society, Vol. 2, No. 1 [2018], Art. 3

"folk theory of language" that promotes an understanding of the meaning of a word as corresponding to "that object in the common everyday world that it maps." With this idea, metaphors have content, and such content is delimited and readily extractable.

In Lakoff's $(1987,121)$ own terms, we might note that in describing his theory of metaphorical coherence, repeated references to containers and conduits, and to the idea that meaning inheres in things and can be mapped, is best understood not as settled orthodoxy in linguistics but instead as a specific and perhaps non-generalizable "folk model" for categorizing and transmitting meaning in language that prioritizes the idea of words and metaphors as sign vehicles. Lakoff's account is, in this sense, as much an expression of culture as it is a means to describe cultures, if in keeping with the semiotics of secrecy I described above. Part of what is at issue here is that the theoretical arrangement of causality governing the relationships among metaphor, cognition, and culture are still up for grabs. Rather than the Lakovian view, which insists that metaphors are vehicles for thought, others continue to make the case that "cultural understanding underlies metaphor use" (Quinn 1991, 56-57). And there are interpretive consequences to Lakoff's culturally specific containment theory of meaning, which I will explore further.

The question of validation of these repositories is also revealing. As the program manager for IARPA's Metaphor project makes clear, each 
metaphorical mapping in a given repository will be validated, with the goal of confirming "native-speaker knowledge of the metaphorical relation" (McCallum-Bayliss 2011. The use of "native-speaker" experts - who are understood to represent competent or fluent speakers of a given language for validation is commonplace in computational linguistics. Mohler, Tomlinson, and Rink (2015) and Neuman et al. (2013), both IARPA-funded, rely on validating their data sets of sentence-level utterances containing metaphors against human annotations. But this type of "native-speaker" validation makes sense only if we treat each language as if it were a reliably monoglot standard, underwritten by reliably consistent metaphorical associations, which would be recognized in the same ways by any typically competent speaker.

However, the notion of linguistic (or cultural) "competence" is controversial among sociolinguists (see Gumperz 1997), as it remains far from clear how to account for speaker knowledge, including the extent to which languages as rule-governed codes are shared, let alone in the same fashion. The problem is the same, if even more vexing, for the concept of "cultural competence," which often equates "cultures" with "programming," and for which efforts to measure and compare "core sets of values" - which are treated as a "patchwork of cultural boxes with quantifiable variables of difference" (see Breidenbach and Nyíri 2009, 270-71) - run up against diverse challenges of intra- and intercultural diversity, uneven distribution, 
and differently contested cultural norms. What is clear, however, is that cultural competence, as a concept, is consistent with the needs of big data approaches to the collection of cultural information.

IARPA, I suggest, conceives of its repositories of metaphors as crosscultural collections of metaphorical commonsense, that is, composed of already recognized and accepted metaphoric relations, informing the predictable parameters - perhaps more accurately, limiting frames or, following Kenneth Burke $(1989,115)$, "terministic screens" - of analogic reasoning for members of a target culture. As I will develop further, this has the potential to be perversely conservative, as IARPA is developing a predictive tool for decision makers that draws upon a compiled cultural aggregate of figurative relationships that are always already assumed to exist. Such a situation makes of prediction, paraphrasing the immortal Yogi Berra, an exercise in déjà vu all over again.

\section{Mapping Cultures, Mapping Brains}

In the spirit of Lakoff's topographical conception of culture, in which meaningful patterns can be organically decomposed into constituent and mappable relations of figure to ground, IARPA relies almost entirely upon the assumption of the conventionality of metaphor. A consequence of its peculiar approach to metaphor, and to culture as a meaningful condition upon how people think, is that IARPA's working conception of its notional publics - the 
people it is trying computational to figure out and anticipate - is seriously limiting. IARPA is "all in" with a conception of metaphor, we might say, stuck in the mode of Durkheim's mechanical solidarity, giving its attention to what are otherwise called "dead metaphors," which one might argue are no longer really metaphors at all.

This tendency is most evident in Lakoff's treatment of so-called "novel" or "poetic metaphors," which receives its greatest elaboration in his 1989 book co-authored with Mark Turner, More than Cool Reason. Here and elsewhere, any seeming metaphoric innovation is understood to rest on highly redundant conventional foundations, using "nothing but the system of conventional metaphor" (Turner 1993, 237), and the pervasiveness of "preexisting metaphorical correspondences" (Turner 1993, 210). Novel or poetic metaphors, in other words, are not so novel nor any different from the metaphors that pervade ordinary speech. Unsurprisingly, and following Lakoff's lead, some IARPA-funded researchers appear not to know what to do with "innovative metaphors." They simply ignore them, because innovative or poetic metaphors create inconvenient "special problems from the point of view of detection and analysis" (Wikberg 2008, 34-35).

The pivotal elision of cultural meaning with convention among computational linguists, and so the ability to standardize and algorithmically code fungible cultural "units" of search and of classification, at once enables their work while drawing attention to its inadequacy. Here is how Heather 
Secrecy and Society, Vol. 2, No. 1 [2018], Art. 3

McCallum-Bayliss (2011) defines "culture" for the purposes of the Metaphor program: "culture is a set of values, attitudes, knowledge and patterned behaviors shared by a group." Cultures are composed - channeling the ghost of Ruth Benedict - of patterned group behavior. The sources for Lakoff's (and IARPA's) understanding of culture are not obvious in his published body of work, though in their classic text, Lakoff and Johnson (1980) credit the influence of such well-known twentieth-century anthropologists as Malinowski, Levi-Strauss, Turner, and Geertz, particularly for their insights regarding "ritual." As well, and not surprisingly, ideas from anthropological linguistics float throughout Lakoff's work, most obviously a strong version of the Sapir-Whorf hypothesis expressing a linguistic relativism governed by complex combinations of foundational metaphors that underlie deeply held beliefs and worldviews, which in turn delineate cultures.

Lakoff's close associate and team member on the MetaNet project, Antón Kövecses (2009), often cites Geertz's $(1973,5)$ ubiquitous "webs of significance" definition of culture, while also defining culture as a shared set of "folk models." Geertz's discussions of cultural "webs" and "texts" - to be semiotically interrogated to reveal their systemic qualities - together with relativistic accounts of interrelationships of language with culture, and widespread mid-twentieth century conceptions of ritual as a structured sequence of words, gestures, or other collective activities, are all directly conversant with approaches to culture and meaning pervasive among 
cognitive linguists, and make an appealing fit for the kinds of information generated by the IC in its mode as a secret society. These ideas are also filtered through psychological approaches to culture, including influences of the mid-twentieth-century "culture and personality" school, with its attention to the relationship between patterned internal states and external behavior. Lakoff's (2002) own book about American politics, Moral Politics: How Liberals and Conservatives Think, is a typical example.

Such a preference for disciplinarily obsolete but hyper-coherent conceptions of culture in the broader military and security environment, in IARPA's case conversant with "cultural and personality"-era formulations, is far from unique. Academic anthropologists, often critical of the national security state, have pointed to the ways in which U.S. agencies have appropriated outdated conceptions of culture from the anthropology of the past (e.g., Albro 2017, Price 2010). At issue is a preference for a concept of culture that is at once bounded, static, coherent, patterned, and shared in the same ways among members, on the one hand, versus a post-critique conception of culture - which currently prevails among anthropologists - as "shifting, contested, constructed, temporal, processual, partial, fluid, heterogeneous, and hybrid" (Albro 2017, 110). Simply put, IARPA and likeminded security agencies prefer the first - if obsolete - version, because it more directly coincides with agency priorities to instrumentalize culture to better predict behavior. 
As Fosher notes $(2014,23)$, this preference for archaic notions of culture reflects an investment in computational and other classificatory tools, which require "cultures" to be "sets of attributes or easily categorized collections of predictably interacting functional elements." Anthropology's more ambivalent recent reception of the culture concept as interpretively contested is largely computationally unmanageable, and so illegible and unpredictable for the purposes of national security analysis.

Much of the problem with cognitive and computational approaches to culture is that they tend to operate with attenuated appreciations of "context," disregarding the ways in which cultures are not aggregates of internal states but instead public. "Context" is often narrowly linguistic, that is, only admitting the collocational trends and syntagmatic content of sentences and other word clusters. The goal is for the wider context of an utterance to have "little to no effect" (Mohler et al. 2015, 123) on its meaning. This has taken its most extreme and reified form with Lakoff's $(2014,5)$ recent turn to neuroscience. He now describes "neural metaphorical mappings," where metaphors are "fixed in the brain" along "pathways ready for metaphor circuitry." Lakoff's marrying of cognitive linguistics to neuroscience has transformed the metaphor concept - a onetime staple of the humanities - into a building block for a new "neural theory of metaphor," (Lakoff 2008, 17) now presented as a scientific tropology, in ways conversant with a growing obsession across U.S. national security 
agencies with the potential of neuroscience.

Given Lakoff's fashionable redressing of his approach to metaphor in the terms of neuroscience, and the technologically enhanced culture concept being engineered by IARPA's Metaphor program, it would not be hard to imagine analysts, as beneficiaries of this data considering how the people they study make decisions, adopting an analytic shorthand to refer to the "Russian brain" or "Farsi brain" in ways reminiscent of the Cold War-era obsession to identify American, Russian, or German "modal personality types." For many anthropologists, research scenarios like these are troubling, because they raise the specter of "how natives think," as well as aggressively "othering." A cynic might go even further to suggest that programs such as this are either purposefully or unintentionally efforts to develop technologies for enemy making.

\section{Metaphor's Multiple Futures}

For IARPA's program to be successful, Lakoff's approach to metaphor has to be uncritically accepted as correct: Linguistic metaphors, assumed to be representative and available in large numbers at the surface of online native-language texts, will be massively mined; their relationships of source to target, it is further taken for granted, will be systematically and reliably mappable; these analogical maps, goes the program's reasoning, will enable identification of more fundamental conceptual metaphors among cultures of 
interest. This in turn will allow analysts to infer relevant cultural patterns that inform the behavior of foreign nationals, and perhaps even help predict their likely decision making on complex topics.

Lakoff on metaphor, in other words, has to be coded into the black box computational tools to be used to build the repositories before any such metaphors are even collected. And Lakovian "metaphor maps" outline the extent of IARPA's data-mining game. This is to say, the theoretical starting point and technological requirements of IARPA's metaphor program are already largely determinative of what "metaphor" can mean for this program. But, as there is not a broad scholarly consensus on how metaphors work, and as one could choose to emphasize other features of the diverse work of metaphor as part of language, perhaps IARPA's choices tell us more about its own world view and cultural point of departure than about how metaphors circulate in the world.

As his work as a political pundit and strategist in recent decades makes clear, Lakoff's heart lies with progressives, but his account of metaphor is in fact deeply conservative. I do not mean conservative in the specifically political sense, but in the ways that Lakoff's approach assumes a specific community of language users, whose expressive potential is understood to be forever circumscribed by an invariant, patterned, coherent, and shared set of metaphorically derived conventions. Ignored or sidelined in IARPA's efforts are competing conceptions of metaphor, which are more 
pragmatically attuned to speech and discourse, and with a more robust appreciation for the various potential effects of surrounding contexts. These competing accounts include attention to the ways in which people variously and creatively argue with, contest, coopt, reclassify, revitalize, or revise the metaphors and meanings they inherit and encounter in order to generate, in Fernandez's $(1986,39-43)$ parlance, new qualities in pronouns.

In his well-known account, Max Black $(1962,29)$ insisted that the interpretation of a metaphor requires attention to "the particular circumstances of its utterance." Black explored the open-endedness of metaphors, which he understood as too unstable to function referentially, and as introducing previously unavailable meanings in the dynamic interplay of figure and ground. Paul Ricoeur (1976), in part building on Black, emphasized how metaphors creatively transform language by revealing new ways to conceive of a referent. As Ricoeur $(1976,53)$ is at pains to make clear, metaphors are events of discourse (not simply of linguistic structure) that bring together incompatible ideas and express irreducible conflicts among multiple interpretations about the world, which help to generate a "surplus of meaning" and provide "new information" - quite different from the repeated repackaging of old information.

Donald Davidson (1978), too, has remained unconvinced that metaphors can function as "propositions" at all, insisting instead that it is a mistake to assume that metaphors possess any particular or stable 
Secrecy and Society, Vol. 2, No. 1 [2018], Art. 3

"meaning." Ricoeur and Davidson on metaphor are reminiscent of a Jasper Johns "flag." Both dismantle expectations of unitary conventional meanings and question otherwise predetermined or, in the case of Johns's "pokerfaced art" and "sphinxlike signs" (Farago 2018), sacred representational relationships (e.g., of flag with nation). Is it a "flag?" Johns asks. We can never be sure. These accounts foreground the properties of metaphors as extensive rather than conventional, and run devastatingly counter to any predictive tropology of the near future.

In contrast to the oft-maintained injunction "against mixed metaphors" (see Pesmen 1991), these accounts instead emphasize the creation of new relations among otherwise "unlike things" and challenge a presumption of coherence by suggesting "impossible worlds" and "impure unions" (Pesmen $1991,216)$ that defy convention. They also compete with and are largely irreconcilable with the Lakovian account. And they complicate IARPA's goals by pointing to the limits of scholarly consensus about the conventionality of metaphor and the ways that any backward-looking exercises in the mapping and archiving of metaphoric relations is at best a partial one that will likely fail to anticipate the future. These alternative stories about metaphor direct attention, instead, to the arguments at the center of cultures (see Fernandez 1986), and to the ways in which metaphors, as emergent and unpredictable, elude our ready classification and animate new inquiry.

To take one case in point, genetics historically has been a field shot 
through with metaphors. Metaphors describing the work of genes are particularly ubiquitous, including: "map," "code," "blueprint," and "recipe," in which DNA is understood to "write" the hereditary possibilities for our biological future. The biologist Richard Dawkins's (1978) influential concept of the "selfish gene," for example, promotes a gene-centric theory of evolution, in which human beings are mere vehicles for successfully selfpropagating individual genes, as the architects of natural selection. But the success of Dawkins's selfish-gene metaphor is beginning to obscure the changing meaning of "gene" (see Rutherford 2016), including a growing variety of technical usages.

Researchers now emphasize the idea of a "post-genomic" biology, in which combinations of networks of less selfish and more managerial genes are also influential, "writing" appears less important than "reading," and the relation of heredity to the environment appears increasingly complex and dynamic. But there are as yet no convincing off-the-shelf metaphors to describe what we continue to learn about the behaviors of genes. In other words, even given the technical and highly shared vocabulary among evolutionary biologists, the shape-shifting of genes under scientific inspection (as Davidson would have it), eludes any reliable conventional description. And whatever metaphors might follow the selfish gene story are as yet unmappable. To insist on a write-only account of the gene today, in other words, is to miss this story. 


\section{Conclusion: Cultures and Black Boxes}

In the era of Wikileaks and Edward Snowden, journalists have increasingly sought to shine a light on "Top Secret America," to borrow Dana Priest and William Arkin's (2012) phrase. And public debate has in large part focused on the new circumstances of privacy (or lack thereof), clandestine data collection, and the ethics of new, largely Internet-based and social media-derived means used by intelligence agencies to amass colossal troves of personal information by mining people's online signatures. Much less considered, if at all, is what kinds of sense the sociological or anthropological theory - the tissue of ideas and concepts - underwriting these programs might make, and what implications these increasingly black-box, algorithmic frameworks might have for the social sciences, in this case dedicated to questions of culture.

The vast majority of attention is given to extolling and further exploring the possibilities for data collection opened up by new computational and social media technologies. Too often, wide-ranging and critically grounded academic discussion and debate have played virtually no part in how these programs are conceived and implemented. A lack of more substantive dialogue about the social science of big-data initiatives in the national security arena increases the possibility of skewed or flawed results. Misguided, if deeply embedded and largely invisible, assumptions have the 
potential to negatively and mischievously - but not altogether obviously influence intelligence priorities in the United States, and if indirectly, the country's foreign policy footprint. In this instance, IARPA's mandate is to develop computationally reliable, predictive cultural analytics that can add value to the agency's goal of "forecasting real-world events in real time" through identifying key "indicators or patterns that tend to surface" (Gunter 2016), like combinations and distributions of metaphors used by foreign publics, even before such events occur. But, I have raised a set of concerns that suggest these goals are deeply problematic.

When academic social scientists do address the social science of the "securityscape," the prevailing approach is to take issue with the politics and ethics of social scientific involvement with the present version of the military industrial complex, advanced from a position well outside this work and often at a considerable distance from its specific details - and many of its implications. But we would also benefit from a more grounded and zoomedin discussion about the epistemologies, research designs, data, analyses, and conclusions drawn by this work and its associated implications, which take account of the ways this realm of social scientific ideas and concepts also drives IC priorities and outcomes in ways sometimes constructive, but perhaps at least as often perverse.

IARPA's attention to culture as a subject of research points to the need for more engaged and critical discussion among social scientists, otherwise 
uninvolved with the national security state, about the agency's typically technology-driven big-data social science and comparable initiatives across the national security community. Such attention could both address and trenchantly appraise the specific assumptions (and social-scientific world view) underwriting these projects, their strengths, and their limits. Typically siloed end users are unlikely to either be aware of or understand in any depth the extent of the "black box" problem posed by algorithms for bigdata collection and analysis built into IARPA's culture projects.

Particularly in a project's early stages, therefore, critiques of linchpin social-scientific concepts with traction in the national security space and embedded in these black boxes can help to temper possible overreach. Such interventions can expose, unpack, and explore important implications of less obvious epistemological starting points, hidden biases, fallacious reasoning, and unintentional misrepresentations by evaluating the extent to which these programs engage with or neglect typically wider-ranging academic discussion and debate about key concepts borrowed from the cultural sciences, such as metaphor. In a way, this is useful in helping nonprogrammer end users, who are likely also unfamiliar with academic debates about the culture concept, to better appreciate the specificity and viability of claims advanced on behalf of the sort of big-data, applied cultural analytics pursued by IARPA and favored in some corners of the national security state. The case of Lakoff's influence upon how IARPA has operationalized its 
metaphor program underscores that we would do well to explore the affinities between the theoretical starting points or frameworks for projects like this one in the intelligence and security world, and the goals of intelligence agencies that rely on academic research. More rigorous attention is needed to the ways such theoretical assumptions might motivate, meaningfully underwrite, and direct programs like this one along certain paths while ignoring others. The conviction that academic knowledge production is objective, value-neutral, scientifically validated, and thus treated as uncontroversial, rather than as contested ideas, is unhelpful in such cases. Such apparent value neutrality discourages closer examination of the ways that some theoretical starting points fit more cozily with the goals of non-academic policy and user communities than do others. It is not by chance that the Lakovian view of metaphor looms so large over IARPA's work on this topic, but such an approach to culture carries with it some deeply troubling implications for how the U.S. security state might identify other societies and cultures. 


\section{References}

Albro, Robert. 2010. "Writing Culture Doctrine: Public Anthropology, Military Policy, and World Making." Perspectives on Politics 8, no. 4: 1087-1093.

. 2011. "Mining Sentiments: Computational Modeling and the Interpretive Problem of Culture." In Challenges in Computational Social Modeling and Simulation for National Security Decision-Making, edited by Charles Gieseler, Laura A. McNamara, and Timothy Guy Trucano, 83108. Defense Threat Reduction Agency Advanced Systems and Concepts Office Report Number ASCO 2011002.

. 2017. "Culture's Iron Cage: U.S. Anthropology, Human Rights, and the Recalcitrant Defense Intellectual." In Human Rights and Humanitarian Intervention: Legitimizing the Use of Force since the 1970s, edited by Norbret Frei, Daniel Stahl, and Annette Weinke, 10726. Göttingen: Wallstein Verlag.

Albro, Robert, and Bill Ivey, eds. 2014. Cultural Awareness in the Military: Developments and Implications for Future Humanitarian Cooperation. New York: Palgrave Macmillan.

Bell, Genevieve. 2015. "The Secret Life of Data." In Data, Now Bigger and Better!, edited by Tom Boellstorff and Bill Maurer, 7-26. Chicago, IL: Prickly Paradigm Press.

Birchall, Clare. 2016. "Six Answers to the Question 'What is Secrecy Studies'." Secrecy and Society 1, no. 1: 1-13. http://scholarworks.sjsu.edu/secrecyandsociety/vol1/iss1/2/

Black, Edwin. 1988. "Secrecy and Disclosure as Rhetorical Forms." Quarterly Journal of Speech 74, no. 2: 133-50.

Black, Max. 1962. Models and Metaphors: Studies in Language and Philosophy. Ithaca, NY: Cornell University Press.

Burke, Kenneth. 1989. On Symbols and Society. Edited by J. Gusfield. Chicago, IL: The University of Chicago Press. 
CENTRA Technology Inc. n.d. Proposer's Day Presentation. Accessed July 23, 2017.

https://www.iarpa.gov/images/files/programs/metaphor/presentations/ CENTRA_Metaphor_Proposers_Day_Presentation.pdf

Comor, Edward. 2017. "Technological Fetishism and U.S. Foreign Policy: The Mediating Role of Digital ICTs." Political Economy of Communication 5(2): 3-21.

Davidson, Donald. 1978. "What Metaphors Mean." Critical Inquiry 5(1): 31-47.

Farago, Jason. 2018. "A Flag Is a Flag Is a Flag." The New York Review of Books, March 22. http://www.nybooks.com/articles/2018/03/22/jasper-johns-flag-is-aflag/

Fernandez, James. 1986. Persuasions and Performances: The Play of Tropes in Culture. Bloomington: Indiana University Press.

Foley, William A. 1997. Anthropological Linguistics: An Introduction. Malden, MA: Blackwell.

Fosher, Kerry. 2014. "Cautionary Tales from the U.S. Department of Defense's Pursuit of Cultural Expertise." In Cultural Awareness in the Military, edited by Robert Albro and Bill Ivey, 15-29. New York: Palgrave Macmillan.

Gandy, Lisa, Nadjii Allan, Mark Atallah, Ophir Frieder, Newton Howard, Sergey Kanareykin, Moshe Koppel, Mark Last, Yair Neuman, and Shlomo Argamon. 2013. "Automatic Identification of Conceptual Metaphors with Limited Knowledge." In Proceedings of the TwentySeventh AAAI Conference on Artificial Intelligence, 328-334. Association for the Advancement of Artificial Intelligence.

Geertz, Clifford. 1973. The Interpretation of Cultures. New York: Basic Books. 
Gumperz, John. 1997. "Communicative Competence." In Sociolinguistics: A Reader, edited by Nikolaus Coupland and Adam Jaworski, 39-48. New York: Palgrave Macmillan.

Gunter, Chase. 2016. "IARPA Seeks to Predict the Unpredictable." FCW: The Business of Federal Technology, October 18. https://fcw.com/articles/2016/10/18/iarpa-predicts-the-future.aspx

Gusterson, Hugh. 2010. "The Culture Turn in the War on Terror." In Anthropology and Global Counterinsurgency, edited by John D. Kelly, Beatrice Jauregui, Sean T. Mitchell, and Jeremy Walton, 279-96. Chicago, IL: The University of Chicago Press.

Holmes-Eber, Paula. 2014. Cultures in Conflict: Irregular Warfare, Cultural Policy, and the Marine Corps. Stanford, CA: Stanford University Press.

IARPA. n.d.a. The IARPA Organization. Accessed July 9, 2018, https://www.iarpa.gov/index.php

. n.d.b. Cyber-attack Automated Unconventional Sensor Environment (CAUSE). Accessed July 9, 2018, https://www.iarpa.gov/index.php/research-programs/cause

. n.d.c. Knowledge Representation in Neural Systems (KRNS). Accessed September 12, 2017. https://www.iarpa.gov/index.php/research-programs/krns

. n.d.d. Reynard. Accessed September 12, 2017.

https://www.iarpa.gov/index.php/research-programs/reynard

. n.d.e. Socio-cultural Content in Language (SCIL). Accessed

September 12, 2017. https://www.iarpa.gov/index.php/researchprograms/scil 
International Computer Science Institute. n.d. MetaNet: A Multilingual Metaphor Repository. Accessed July 16, 2018. https://www.icsi.berkeley.edu/icsi/gazette/2012/05/metanet-project_

Johnston, Rob. 2005. Analytic Culture in the U.S. Intelligence Community: An Ethnographic Study. Washington, DC: Central Intelligence Agency. https://www.cia.gov/library/center-for-the-study-of-intelligence/csipublications/books-and-monographs/analytic-culture-in-the-u-sintelligence-community/analytic_culture_report.pdf

Kövecses, Antón. 2009. "Metaphorical Meaning Making: Discourse, Language, and Culture." Quaderns de Filologia. Estudis lingüístics XIV: 135-51.

Lakoff, George. 1987. Women, Fire, and Dangerous Things: What Categories Reveal about the Mind. Chicago, IL: University of Chicago Press.

. 1993. "The Contemporary Theory of Metaphor." In Metaphor and Thought, edited by Ning Yu, 202-51. Cambridge, UK: Cambridge University Press.

. 2002. Moral Politics: How Liberals and Conservatives Think. Chicago, IL: The University of Chicago Press.

. 2014. "Mapping the Brain's Metaphor Circuitry: Metaphorical Thought in Everyday Reason." Frontiers in Human Neuroscience 8, no. 958: 114. https://www.ncbi.nlm.nih.gov/pmc/articles/PMC4267278/

Lakoff, George and Mark Turner. 1980. Metaphors We Live By. Chicago, IL: University of Chicago Press. 1989. More than Cool Reason: A Field Guide to Poetic Metaphor. Chicago, IL: University of Chicago Press. 
Secrecy and Society, Vol. 2, No. 1 [2018], Art. 3

Logan, Sarah. 2017. "The Needle and the Damage Done: Of Haystacks and Anxious Panopticons." Big Data \& Society July-December: 1-13. http://journals.sagepub.com/doi/pdf/10.1177/2053951717734574

Masco, Joseph. 2010. "'Sensitive but Unclassified': Secrecy and the Counterterrorist State." Public Culture 22, no.3: 433-63.

Maret, Susan. 2016. "The Charm of Secrecy: Secrecy and Society as Secrecy Studies." Secrecy and Society 1, no. 1: 1-28. http://scholarworks.sjsu.edu/secrecyandsociety/vol1/iss1/1/

McCallum-Bayliss, Heather. 2011. IARPA Metaphor Proposer's Day Brief. Office of Incisive Analysis. Washington: Office of the Director of National Intelligence. https://www.iarpa.gov/images/files/programs/ metaphor/Metaphor_Proposers_Day_Brief.pdf

Mohler, Michael, Marc Tomlinson and Bryan Rink. 2015. "Cross-lingual Semantic Generalization for the Detection of Metaphor." International Journal of Computational Linguistics and Applications 6, no. 2: 117-40.

Narayanan, Srini. 2012. MetaNet: A Multilingual Metaphor Extraction, Representation, and Validation System. PowerPoint presentation. http://www.icsi.berkeley.edu/pubs/ai/BEARS2012_narayananslides.pdf

National Research Council. 2011. Sociocultural Data to Accomplish Department of Defense Missions. Washington: The National Academies Press. https://www.nap.edu/catalog/13077/sociocultural-data-toaccomplish-department-of-defense-missions-toward-a

Neuman, Yair, Dan Assaf, Yohai Cohen, Mark Last, Shlomo Argamon, Newton Howard, and Ophir Frieder. 2013. "Metaphor Identification in Large Texts Corpora." PLOS ONE: 1-7. http://journals. plos.org/plosone/article?id=10.1371/ journal.pone.0062343

Nietzsche, Friedrich. 1999. "On Truth and Lies in a Non-Moral Sense." In The Birth of Tragedy and Other Writings, edited by Raymond Geuss and Ronald Speirs, 139-53. Cambridge, UK: Cambridge University Press. 
Ophir, Shai. 2016. "Big Data for the Humanities Using Google Ngrams: Discovering Hidden Patterns of Conceptual Trends." First Monday 21, no.7. http://firstmonday.org/ojs/index.php/fm/article/view/5567/5535

Pesmen, Dale. 1991. "Reasonable and Unreasonable Worlds: Some Expectations of Coherence in Culture Implied by the Prohibition of Mixed Metaphors." In Beyond Metaphor: The Theory of Tropes in Anthropology, edited by James W. Fernandez, 213-43. Stanford, CA: Stanford University Press.

Plemmons, Dena, and Robert Albro. 2012. "Practicing Ethics and Ethical Practice: The Case of Anthropologists and Military Humanitarians." Humanity 2, no.2: 179-97.

Price, David. 2010. "The Army's Take on Culture." Anthropology Now 2, no. 1 : 57-63.

Priest, Dana, and William M. Arkin. 2012. Top Secret America: The Rise of the New American Security State. New York: Little, Brown and Company.

Quinn, Naomi. 1991. "The Cultural Basis of Metaphor." In Beyond Metaphor: The Theory of Tropes in Anthropology, edited by James W. Fernandez, 56-93. Stanford, CA: Stanford University Press.

Ricoeur, Paul. 1976. Interpretation Theory: Discourse and the Surplus of Meaning. Fort Worth, TX: Texas Christian University Press.

Rutherford, Adam. 2016. "As Long as We Study Life, It Will Be Read: The Selfish Gene Turns 40." The Guardian, May 29. https://www.theguardian.com/science/2016/may/29/selfish-gene-40years-richard-dawkins-do-ideas-stand-up-adam-rutherford

Shrader, Katherine. 2007. "New Agency IARPA Develops Spy Tools." Washington Post, May 31. http://www.washingtonpost.com/wpdyn/content/article/2007/05/31/AR2007053100185.html?noredirect=on 
Shutova, Ekaterina. 2010. "Models of Metaphor in NLP." In Proceedings of the 48th Annual Meeting of the Association for Computational Linguistics, 688-97, Uppsala, Sweden: Association for Computational Linguistics.

Simonite, Tom. 2017. "AI Experts Want to End 'Black Box' Algorithms in Government." Wired, October 18. https://www.wired.com/story/aiexperts-want-to-end-black-box-algorithms-in-government/

Weinberger, Sharon. 2011. "Spies to Use Twitter as Crystal Ball." Nature 478 (301). https://www.nature.com/news/2011/111017/full/478301a.html

Wikberg, Kay. 2008. "The Role of Corpus Studies in Metaphor Research." In Selected Papers from the 2006 and 2007 Stockholm Metaphor Festivals, edited by Nils-Lennart Johannesson and David C, Minugh, 3348. Stockholm: Department of English, Stockholm University. 